\title{
PRECONCEITO CULTURAL E O (RE)CONHECIMENTO DE DIREITOS
}

CULTURAL PREJUDICE AND KNOWLEDGE/ACKNOWLEDGEMENT OF RIGHTS

EL PREJUICIO CULTURAL Y EL (RE)CONOCIMIENTO DE DERECHOS

Daniel Rubens Cenci ${ }^{1}$

Aline Andrighetto²

1 Doutor em Meio Ambiente e Desenvolvimento; Professor do Departamento de Ciências Jurídicas e Sociais e do Programa de Pós-Graduação Mestrado em Direitos Humanos da Universidade Regional do Noroeste do Rio Grande do Sul - UNIJUI; Coordenador da Linha de Pesquisa Direitos Humanos, Meio Ambiente e Novos Direitos; Coordenador do projeto de pesquisa CNPq "O direito ambiental no contexto da sociedade de risco: em busca da justiça ambiental e da sustentabilidade"; Coordenador do Projeto COMPARTE - sobre democracia e gestão participativa, com Universidades UNAM - Manágua, Nicarágua juntamente com Universidades de Madrid e Barcelona na Espanha. danielr@unijui.edu.br

2 Doutoranda em Direito pela UNISINOS. Mestre em Direito pela Universidade Regional Integrada do Alto Uruguai e das Missões (URI); Membro do grupo de pesquisa "Novos direitos na sociedade globalizada"; registrada no CNPq e base de sustentação da linha de pesquisa "Direito e Multiculturalismo" do Mestrado da URI, Santo Ângelo. 
Resumo: O presente artigo procura explicar a importância do reconhecimento de identidades culturais para o papel democrático no Brasil e sua importância para a perspectiva da concepção liberal de democracia e a reconstrução da política, que deve atender à sociedade civil no que se refere às intervenções na sociedade. Menciona alguns pontos na história do país onde se evidenciam ideais de preconceito contra a sociedade. Demonstra o caso mais recente e público de discriminação e preconceito ocorrido na Justiça Federal do Rio de Janeiro, por meio de decisão judicial, em que fora proferida sentença sobre vídeos ofensivos, de cunho racista, publicados na internet. Procura demonstrar na legislação vigente a proteção dos grupos vulneráveis a estas práticas abusivas, no tocante a noções de garantia e proteção para uma sociedade mais justa e solidária. Importante também se faz reconhecer que o direito de culto reconhecido pela Constituição Federal se faça valer, afim de que se possa construir o papel social da religião e compreender de que maneira as noções dos homens e as suas disposições induzem a um sentido racional, humano e moral de respeito a todas as culturas étnicas.

Palavras- chave: Identidade. Reconhecimento. Cultura. Racismo.

Abstract: This paper seeks to explain the importance of recognizing cultural identities for the democratic role in Brazil, and their importance for the perspective of the liberal concept of democracy and the reconstruction of the policy, which should serve the civil society with regard to interventions in society. It mentions some points in the history of the country where ideals of prejudice against society were seen. It demonstrates the most recent, and public case of discrimination and prejudice that occurred in the Federal Court of Rio de Janeiro, through a court decision, which was handed down in judgment on offensive, racist videos published on the internet. This article seeks to demonstrate, in the current legislation, the protection of groups that are vulnerable to these abusive practices, and how they are related to the notions of guarantee and protection for a more just and caring society. Is also important to recognize that the right to worship recognized 
by the Federal Constitution is enforced, so that we can build the social role of religion, and understand how the notions of men, and its provisions which induce a rational, human and moral sense in relation to all ethnic cultures.

Keywords: Identity. Acknowledgement. Culture. Racism.

Resumen: El presente artículo procura explicar la importancia del reconocimiento de identidades culturales para el papel democrático en Brasil y su importancia para la perspectiva de la concepción liberal de democracia y la reconstrucción de la política, que debe atender a la sociedad civil en lo que se refiere a las intervenciones en la sociedad. Se mencionan algunos puntos en la historia del país donde se evidencian ideales de prejuicio contra la sociedad. Se expone el caso más reciente y público de discriminación y prejuicio ocurrido en la Justicia Federal de Rio de Janeiro, por medio de decisión judicial, en el que fue proferida sentencia sobre vídeos ofensivos, de cuño racista, publicados en la internet. Se intenta demostrar en la legislación vigente la protección de los grupos vulnerables a estas prácticas abusivas en lo tocante a nociones de garantía y protección para una sociedad más justa y solidaria. También se vuelve importante reconocer que se debe hacer valer el derecho de culto reconocido por la Constitución Federal, a fin de que se pueda construir el papel social de la religión y comprender de qué manera las nociones de los hombres y sus disposiciones inducen a un sentido racional, humano y moral de respeto a todas las culturas étnicas.

Palabras clave: Identidad. Reconocimiento. Cultura. Racismo.

\section{INTRODUÇÃO}

necessidade de reconhecimento dos direitos do grupo minoritário
afrodescentente, especificamente a ser abordado no presente
artigo, frente a preceitos de desigualdade, dignidade, respeito e descumprimento de direitos fundamentais em âmbito nacional e descumprimento 
dos Direitos Humanos, caracteriza-se como hipótese. Neste sentido, compreendese que práticas e estudos são de grande importância para dirimir fatores políticos e ideológicos sobre o tema no Brasil.

Em um primeiro momento, faz-se importante mencionar a identidade do ser humano e suas diferenças. A tentativa de compreender biológica e socialmente a realidade das coisas e dos meios faz parte de uma preconcepção do processo de efetivação da identidade e da diferença. Identificar, portanto, significa reconhecer um objeto por meio da determinação de invariáveis, cujas características determinam a coisa na sua unidade e individualidade durante o tempo de sua existência.

Por outro lado, diferenciar significa estabelecer variações que não são determinantes a um objeto como indivíduo, mas que determinam uma mínima lógica que pressupõe um preparo de informações, como racionalização primeira e originária da natureza. Por isso, torna-se difícil, muitas vezes, situar quem é quem no jogo das diferenças, nas relações desiguais de poder, de quem se posiciona na condição de dominante ou de dominado, uma vez que em todos os grupos culturais existem os discriminados e os discriminadores.

Mencionar questões como reconhecimento e diferença é necessário, na perspectiva da concepção liberal de democracia. A reconstrução da política deve atender à sociedade civil no que se refere às intervenções na sociedade política à qual está subordinada. Dessa forma, o pensamento democrático se transformará fortemente. O que o artigo busca é mencionar por meio de sentença proferida em caso recente sobre violação de liberdade a culto religioso a necessidade de se rever o aparato judicial existente e o reconhecimento por parte do poder judiciário dos grupos minoritários, os quais devem em sua máxima proteção e respeito, reconhecendo direitos históricos e legados deixados pelos povos que habitaram o Brasil. Menciona que a religiosidade é de suma importância para o processo de reconhecimento da identidade, pois governa a vida espiritual do homem e mantém entre eles um conjunto de práticas. No que se refere à população negra, é importante ressaltar as condições históricas as quais os ligam à sociedade brasileira. 
O objetivo deste artigo é demonstrar o poder que a influência da religiosidade exerce sobre a sociedade por meio de suas raízes históricas e como a sociedade atual aceita esta cultura tornando o grupo afrodescendente diminuído e desvalorizado frente a uma sociedade discriminadora.

A metodologia empregada é de pesquisa bibliográfica em conjunto com técnica de análise observacional de jurisprudência da Justiça Federal do Rio de Janeiro.

\section{NECESSIDADE DE RECONHECER}

O ser humano deve ser visto como alguém que precisamente, por meio da aceitação de outros, se sente reconhecido e, consequentemente, em comunhão com estes, possibilitando a sua disposição de igualmente reconhecer o outro em sua originalidade e singularidade. "[...] movimentos de emancipação também visam a superação de uma cisão ilegítima da sociedade, a autocompreensão da cultura pode não sair ilesa" ${ }^{3}$. Isto porque a compreensão do outro em suas relações e interesses necessita de uma reinterpretação do papel do homem.

Há uma diferenciação quando se trata de reivindicar reconhecimento para identidades coletivas ou igualdade de direitos culturais. Isto porque sociedades multiculturais, ou povos que no passado lutavam por independência e autonomia, hoje lutam por igualdade de direitos. O reconhecimento da forma de vida e das tradições culturais exige garantias de status ou sobrevivência.

Taylor menciona que "a exigência faz-se sentir, na política de hoje, de determinadas formas, em nome dos grupos minoritários ou subalternos, em algumas manifestações de feminismo e naquilo que agora na política se designa multiculturalismo"4.

Para Honneth:

Uma forma tradicional de reconhecimento jurídico dessa espécie já concede ao sujeito, como vimos, uma proteção social para sua 'dignidade' humana; mas esta está ainda inteiramente fundida com

3 HABERMAS, Jürgen. A inclusão do outro: estudos de teoria política. Edições Loyola. São Paulo. 2002, p.239.

4 TAYLOR, Charles. Multiculturalismo. Lisboa, Portugal: Instituto Piaget, 1994, p.45. 
o papel social que lhe compete no quadro de uma distribuição de direitos e encargos amplamente desigual ${ }^{5}$.

Há uma necessidade permanente de valorização de igualdade entre os sujeitos, pois quando há a interligação entre Estado de Direito e Democracia, é possível que o sistema venha a ensejar condições de vida social menos desiguais para as diferentes identidades culturais hipossuficientes.

Honneth afirma ainda que a autocompreensão cultural de uma sociedade determina critérios pelos quais se orienta a estima social das pessoas, já que suas capacidades e realizações são julgadas intersubjetivamente, à medida que cooperam na implementação de valores culturalmente definidos. Por outro lado, a forma de reconhecimento está ligada também à pressuposição de um contexto de vida social, cujos membros constituem uma comunidade de valores mediante a orientação por concepções de objetivos comuns ${ }^{6}$.

É nesse sentido que surgem os questionamentos acerca da diversidade de identidades, como devem ser definidas, e se devem ser relacionadas especificamente com as culturas. A tendência para a consolidação e a difusão de uma ou de algumas poucas linhas de força de alcance global surge como mais nítida no campo da economia do que no campo da cultura. Esse quadro relativo à identidade cultural não se manifesta apenas no chamado mundo subdesenvolvido ou em desenvolvimento. Existem alguns parâmetros culturais, os quais devem ser observados para se identificar as diferenças a partir de uma economia. D'Adesky menciona neste sentido que se pode identificar a raça, a religião e a língua como fatores fundamentais, a história como o epicentro de uma herança cultural comum, de maneira que a consciência de pertencimento e a vontade de viver em conjunto tonam-se expressões de determinada comunidade cultural ${ }^{7}$.

No sentido de verificar identidades culturais, há de se falar em vários modos que aparecem como reveladores de tempos de crises e de imprevisibilidades. Sem dúvida, o nacionalismo assim como o racismo canaliza reações e sentimentos 5 HONNETH, Axel. Luta por reconhecimento: a gramática moral dos conflitos sociais. Trad. de Luiz Pepa. São Paulo: Ed. 34, 2003, p.181.

6 HONNETH, Axel. Luta por reconhecimento: a gramática moral dos conflitos sociais. Trad. de Luiz Pepa. São Paulo: Ed. 34, 2003, p.200.

7 D'ADESKY, Jacques. Pluralismo étnico e multiculturalismo: racismos e anti-racismos no Brasil. Rio de Janeiro: Pallas, 2009, p.38. 
distintos. O retorno às origens culturais e suas reações por parte das nações pode traduzir a perda das certezas na ideia de progresso, ou seja, o sentimento de perda de um futuro. Hall expressa:

As identidades nacionais, como vimos, representam vínculos a lugares, eventos, símbolos, histórias particulares. Elas representam o que algumas vezes é chamado de uma forma particularista de vínculo ou pertencimento. Sempre houve uma tensão entre essas identificações e identificações mais universalistas - por exemplo, uma identificação maior com a "humanidade" do que com a "inglesidade" (englishness $)^{8}$.

O estudo sobre a origem das nações e o retorno às reivindicações culturais dos povos teve por consequência a revalorização do paradigma das identidades junto às Ciências Humanas. O culto do passado predispôs a própria disciplina de História a se mobilizar na construção de memórias e de identidades particulares. Esse fato adquiriu uma dimensão inédita no mundo, em que se inventam entidades nacionais encontradas na construção de um passado.

O que se percebe, falando em diversidade, é que as demandas multiculturais vêm crescendo cada vez mais e proporcionam uma crescente ampliação nos direitos constitucionais na maioria dos Estados. Não bastam, entretanto, as lutas pelo reconhecimento serem traduzidas em termos normativos constitucionais, mas também em termos de ações políticas no campo institucional mediante a realização de políticas públicas que buscam afirmar e administrar as diferenças culturais, e de identidade utilizando estratégias que contemplem componentes linguísticos, sociais, econômicos, educativos, entre outros. Segundo menciona Geertz:

[...] a antropologia tem tentado encontrar o seu caminho para um conceito mais viável sobre o homem, no qual a cultura e a variabilidade cultural possam ser mais levadas em conta do que concebidas como capricho ou preconceito e, no entanto, ao mesmo tempo, um conceito no qual o principio dominante na área, "a unidade básica da humanidade", não seja transformado numa expressão vazia".

8 HALL, Stuart. A identidade cultural na pós-modernidade. 11. ed. Trad. Tomaz Tadeu da Silva e Guacira Lopes Louro. Rio de Janeiro: DP\&A, 2006, p.76.

9 GEERTZ, Clifford. A interpretação das culturas. LTC Editora, Rio de Janeiro, RJ. 1989, p.27. 
Nesse sentido, a centralidade do Direito, quando relacionada a diversidades multiculturais, é vista não somente com um mecanismo de regulação social. Torna-se necessário destacar que as políticas de reconhecimento, tanto em termos normativos constitucionais como em termos de políticas públicas, apresentam alguns problemas, como, por exemplo, as demandas particulares que transformam direitos em diferenças culturais, muitas vezes podendo sobrecarregar o Estado com uma pressão social cuja legitimidade este não possa instaurar em função da falta de instrumentos políticos.

A história cultural substitui a ambígua história das mentalidades. Pode-se dizer que os conceitos de cidadania trouxeram realidades diferentes à pessoa que prezam muito mais pelos ideais de igualdade e interessa-se por outros níveis de análise, como algumas noções de comunicação distintas que implicam: a transmissão, a aquisição, o dito, o pensado, o imaginado e o criado.

No que concerne ao contexto brasileiro à questão cultural e às interrogações inerentes aos efeitos da globalização, tem-se que o fenômeno da globalização acentua o sentimento de perda de identidade, ou seja, em um mundo de metamorfoses, se a globalização proporciona novas solidariedades planetárias, como ecologia e direitos humanos, elas devem reforçar as necessidades de reconhecimento das diferenças. Segundo Geertz:

Os usos da diversidade cultural, de seu estudo, sua descrição, sua analise e sua compreensão, têm menos o sentido de nos separarmos dos outros e separarmos os outros de nós, a fim de defender a integridade grupal e manter a lealdade do grupo, do que o sentido de definir o campo que a razão precisa atravessar, para que suas modestas recompensas sejam alcançadas e se concretizem ${ }^{10}$.

Num mundo sem fronteiras e sem referências, a busca por identidades se acelera, favorecendo múltiplas solidariedades, portadoras de identidades de substituição, em níveis nacional, local e individual, podendo modificar os modos de vida das pessoas e a própria cultura, ou seja, a globalização provoca uma fragmentação e uma uniformização. Desse sentimento de instabilidade, que

10 GEERTZ, Clifford. Nova luz sobre a antropologia. Rio de Janeiro: Jorge Zahar Ed., 2001, p.81. 
conduz o indivíduo a incessantes tomadas de riscos, resultam os "mal-estares" da identidade contemporânea, como bem constata Giddens ${ }^{11}$.

Enfim, o que se pode concluir é que o conhecimento é que leva o homem a crescer dentro de seu grupo, o que de certo modo faz com que se crie uma integração cultural, melhorando as relações e buscando sanar diferenças com respeito às exigências e às potencialidades de um povo.

\section{HISTÓRIA E DISCRIMINAÇÃO DE UM POVO}

A história do Brasil no período Colonial menciona a discriminação e o preconceito existentes no país desde o seu início. Em 1822, ao proclamar a independência de Portugal, o Brasil ainda mantinha mão de obra escravista baseada na exploração do homem e da sua força de trabalho, que era vista como propriedade privada de quem a comprava.

A sociedade escravocrata era uma ordem social com base na produção e na utilização da força de trabalho de afrodescendentes escravos. Ao longo dos tempos, os portugueses povoaram um país com grandes dimensões, o qual possuía unidade territorial, idioma próprio, cultura e religião. A herança dessa exploração portuguesa foi uma população carente de uma formação cidadã, onde se desconsiderou a dignidade da pessoa humana. Não houve a preocupação de construir uma sociedade republicana, pois aos conquistadores preponderou a intenção de obter riquezas e retornar ao seu país ${ }^{12}$.

Os nativos habitavam o território brasileiro quando aqui aportaram os portugueses. Vivendo em grupos, falavam diversas línguas e apresentavam vários estágios de organização. Praticavam a agricultura e a sua economia era de subsistência. Com o processo de colonização foram reduzidos a pequenos grupos e suas terras invadidas/ usurpadas. Os portugueses atuavam como os novos proprietários e receberam, por via do tráfego, milhões de africanos para o trabalho escravo.

11 GIDDENS, Anthony. As consequências da modernidade. São Paulo: Ed. Unesp, 1991.

12 WILLEMAN, Estela Martini; LIMA, Guiomar Rodrigues de. O preconceito e a discriminação racial nas religiões de matriz africana no Brasil. Disponível em: <http://www. uniabeu.edu.br/publica/index.php/RU/article/view/60/120>. Acesso em: 19 de set. 2012. 
Os africanos possuíam sua própria cultura, pois eram nações diferentes que aqui se faziam representar por meio das suas várias e diversas características tanto culturais quanto religiosas. A religião deste povo foi fundamental para a resistência e conservação de aspectos culturais e contribuiu para a construção da identidade e da solidariedade. A noção de territorialidade como espaço de reprodução cultural, social, religiosa, ancestral e econômica põe em xeque a visão tradicional que associa terra e pura utilidade econômica. São comunidades a reivindicar o "pleno exercício dos direitos culturais", no qual o seu "território" é elemento essencial ${ }^{13}$.

Sabe-se que muito do culto religioso existente hoje no Brasil é fruto da cultura africana. No Brasil Colônia, os escravos eram impedidos de cultuar suas divindades, e para exercer seus cultos, sua língua e suas práticas, muitas vezes precisavam fingir o culto católico, o que garantiu a permanência de sua cultura até a atualidade. Por si só isso já justifica a quebra do preconceito do branco contra o negro. Além disso, a proibição do exercício do idioma, bem como da autoidentificação por seu próprio nome de batismo, foi comum durante toda a escravidão, o que provocou a perda de muito das características de identidade deste povo, as quais foram cerceadas e até mesmo tornadas crime - como o caso da capoeira ${ }^{14}$.

Depois de formalmente abolida a escravatura, iniciaram-se casos de segregação violenta com a intervenção policial e de outras autoridades de templos, já que o Brasil racista sempre se autoproclamou católico. Percebe-se, então, que a cultura africana se coloca de maneira muito importante no que diz respeito às crenças hoje perpetuadas, pois advém de um conjunto de mitos e cultos. Segundo Canclini:

As teorias do étnico e do nacional são, em geral, teorias das diferenças. Por outro lado, o marxismo e outras correntes macrossociológicas (tais como as que se ocupam do imperialismo e da dependência) dedicamse à desigualdade. Em alguns autores encontram-se combinações de ambos os enfoques, como certos enfoques do nacional em estudos sobre o imperialismo ou contribuições à compreensão do capitalismo em especialistas da questão indígena. Quanto aos estudos sobre

13 BALDI, César Augusto. Justiça Federal: Racismo, terras e Direitos Humanos. 2010. Disponível em: http://democraciaejustica.org/cienciapolitica3/sites/default/files/justica_federal _ racismo_terras_e_direitos_humanos_-_cesar_baldi_2010.pdf. Acesso em: 25 maio 2014, p.2.

14 WILLEMAN, Estela Martini; LIMA, Guiomar Rodrigues de. O preconceito e a discriminação racial nas religiões de matriz africana no Brasil. Disponível em: < http://www.uniabeu.edu.br/ publica/index.php/RU/article/view/60/120>. Acesso em: 19 de set. 2012. 
conectividadeedesconexão, concentram-senoscamposcomunicacional e informático, com escasso impacto nas teorias socioculturais ${ }^{15}$.

Alguns fatores concorreram para desestabilizar a imagem de paraíso que detinha o Brasil, cuja origem provém das elites brancas criadas por cientistas sociais. A democracia racial foi um dos maiores e mais poderosos mecanismos de dominação ideológica produzidos no mundo ${ }^{16}$.

Depreende-se, contudo, que a língua tem oferecido aos negros e aos mestiços no país uma estrutura de inteligência no sentido de compreenderem a própria existência por meio de experiências vividas em um momento de confusão entre inclusão e exclusão. Sabe-se que a democracia, naquele período, favoreceu àqueles que dela obtiveram vantagens econômicas, sociais e políticas. Foram os negros e os mestiços que ao adentrarem na sociedade organizaram movimentos de protesto para denunciá-lo. Gohn coloca que:

A presença dos movimentos sociais é uma constante na história política do país, mas ela é cheia de ciclos, com fluxos ascendentes e refluxos (alguns estratégicos, de resistência ou rearticulação em face à nova conjuntura e às novas forças sociopolíticas em ação) ${ }^{17}$.

Na história brasileira percebe-se que organizações negras são muito centradas, lideradas por pequenos grupos que se destacaram em projetos políticos a fim de reivindicar melhores oportunidades para a sociedade, como: mudanças nos padrões sociais, reivindicando direitos iguais e possibilidade de receber o mesmo tratamento de imigrantes europeus ${ }^{18}$.

Até um passado recente, a necessidade de consciência do problema da discriminação não era um fenômeno isolado da estrutura de poder brasileira, mas colocava em questão o sistema de representações étnicas em vigor naquele momento, pois o que a elite branca mais temia era que negros e mestiços

15 CANCLINI, Néstor Garcia. Diferentes, desiguais e desconectados: mapas da interculturalidade. 3. ed. Rio de Janeiro: Ed. da UFRJ, 2009, p.55.

16 GONÇALVES, Luiz Alberto Oliveira; SILVA, Petronilha B. Gonçalves e. O jogo das diferenças: o multiculturalismo e seus contextos. 4. ed. Belo Horizonte: Autêntica, 2006, p.67.

17 GOHN, Maria da Glória. Movimentos sociais e redes de mobilizações civis no Brasil contemporâneo. 2. ed. Petrópolis, RJ: Vozes, 2010, p.41.

18 GONÇALVES, Luiz Alberto Oliveira; SILVA, Petronilha B. Gonçalves e. O jogo das diferenças: o multiculturalismo e seus contextos. 4. ed. Belo Horizonte: Autêntica, 2006, p.69. 
ocupassem cargos de poder.

Com base na legislação e com tantas preocupações relacionadas às minorias étnicas, pode-se dizer que o Brasil possui uma diversidade muito vasta e deve sim preocupar-se em preservar e defender as raízes do país que hoje possui uma diversidade de valores. Há de se pensar no grande absurdo que se comete transformando esta riqueza em opressão e luta.

Pode-se mencionar nesse sentido a Lei $n^{0} 7.716 / 1989$, a qual refere crimes resultantes de preconceito de raça ou de cor, que deve ser divulgada e incorporada na busca pelos direitos das minorias e no combate da discriminação. No Brasil não há respostas sociais e econômicas para as desigualdades sociais, tampouco para as diferenças e as agressões, especialmente para aquelas que decorrem de condutas ou atitudes preconceituosas e discriminatórias. É preciso acabar com os problemas que criminalizam condutas, pois há compulsão em criminalizá-las, ao mesmo tempo em que são banalizadas as situações, asseverando que cadeia é a solução para todos os males ou ameaças. Como consequência, estabelecemse punições severas, fazendo com que os juízes nunca as apliquem às pessoas encontradas em culpa. Essa lei que criminaliza as condutas é obtusa, porque não enfrenta a gravidade do problema da discriminação e do preconceito no Brasil.

O Código Penal, em seu art. 140, estabelece a possibilidade de criminalização de agressão verbal como injúria. Neste sentido, cabe atentar para dois artigos da Constituição Federal de 1988, o Art. 215, que menciona que o Estado garantirá a todos o pleno exercício dos direitos culturais e acesso às fontes da cultura nacional, e apoiará e incentivará a valorização e a difusão das manifestações culturais. Segundo menciona o referido artigo, todos são tratados como iguais no sentido da dignidade essencial de sua contribuição cultural, incluindo-se aí as minorias.

Já o art. 216 determina que o patrimônio cultural brasileiro, os bens de natureza material e imaterial, individuais ou e conjunto são formadores da sociedade brasileira. A Constituição de 1988, ao contrário das anteriores, e ainda que não tenha utilizado qualquer terminologia de "multicultural" ou "intercultural", estabelece premissas e coordenadas para pensar a diversidade étnico-racial, 
social e cultural em patamares diferenciados ${ }^{19}$.

Sua interpretação leva a concluir que uma pedra é uma pedra, mas se for uma pedra insculpida, pintada ou lavrada, é um bem cultural. Assim também um tronco de árvore; mas se for um tronco trabalhado que se converta em um totem, em uma escultura ou em um adereço, passa a ser produto da cultura. Então, todos esses, "individualmente ou em conjunto, portadores de referência à identidade, à memória, à ação dos diferentes grupos formadores da sociedade", são patrimônio cultural brasileiro, e devem ser respeitados e tratados de forma respeitosa de acordo com sua cultura e costumes.

O Estatuto da Igualdade Racial (Lei n. 12.288/2010) foi aprovado para dirimir questões e dúvidas sobre igualdade e intolerância étnica, o qual foi designado para garantir à população negra a efetivação da igualdade de oportunidades, a defesa dos direitos étnicos individuais, coletivos e difusos e o combate à discriminação e as demais formas de intolerância étnica.

O referido Estatuto menciona ainda que é dever do Estado e da sociedade garantir a igualdade de oportunidades, reconhecendo a todo cidadão brasileiro, independentemente da etnia ou da cor da sua pele, o direito à participação na comunidade, especialmente nas atividades políticas, econômicas, empresariais, educacionais, culturais e esportivas, defendendo sua dignidade e seus valores religiosos e culturais. Com relação às normas constitucionais relativas aos princípios fundamentais, aos direitos, às garantias fundamentais e aos direitos sociais, econômicos e culturais, o documento adota uma diretriz política e jurídica, bem como orienta a inclusão das vítimas da desigualdade étnico-racial, a valorização da igualdade étnica e o fortalecimento da identidade nacional brasileira. Percebese, com isso, que os direitos das minorias estão sendo reconhecidos de maneira gradativa e com instrumentos hábeis e facilitadores. O homem precisa entender a respeitar o semelhante, mesmo que seja sob a força normativa.

Estabelece um repensar do conceito de "comunidade tradicional" (conceito existente na Convenção 169-OIT, da qual o Brasil é signatário), rompendo com:

19 BALDI, César Augusto. Justiça Federal: Racismo, terras e Direitos Humanos. 2010. Disponível em: http://democraciaejustica.org/cienciapolitica3/sites/default/files/justica_federal_ racismo_terras_e_direitos_humanos_-_cesar_baldi_2010.pdf. Acesso em: 25 maio 2014. 
a) o pensamento eurocêntrico que parte do pressuposto de que o conhecimento tradicional associado (e toda a fitoterapia relacionada), a cosmologias étnicas, a associação com a presença indígena ou negra, as especificidade cultural, o manejo sustentável da economia são símbolos de que tais saberes, temporalidades, diferenças e escalas são inferiores e, portanto, devem manter-se ignorados, silenciados, eliminados e/ou condenados à inexistência ou à irrelevância; b) o etnocentrismo, que entende as culturas como atemporais - ou quando distintas, como "presas ao passado" - e, portanto, impossíveis de serem alteradas.

As "comunidades tradicionais" - das quais os quilombolas, faxinalenses e ribeirinhos são exemplos - não são representantes de um passado, nem "vestígio", nem meros "remanescentes": são parte da estrutura agrária do presente e tão modernas e contemporâneas quanto os agricultores que utilizam transgênicos ou os pesquisadores de células-tronco. Mais que isto: a insistência no critério de autodefinição (como previsto na Convenção $n^{\circ}$ 169-OIT) é outro elemento questionador do etnocentrismo da sociedade - os critérios de "classificação social" são, em geral, fruto de "heterodefinição" (de que "negro" e "homossexual" são casos clássicos)²0.

Ações afirmativas são medidas especiais tomadas com o objetivo de assegurar progresso adequado de certos grupos raciais, sociais ou étnicos ou indivíduos que necessitem de proteção, e que possam ser necessárias e úteis para proporcionar a tais grupos ou indivíduos igual gozo ou exercício de direitos humanos e liberdades fundamentais, contanto que tais medidas não conduzam, em consequência, à manutenção de direitos separados para diferentes grupos raciais, e não prossigam após terem sido alcançados os seus objetivos. "A constituição faz valer exatamente os direitos que os cidadãos precisam reconhecer mutuamente, caso queiram regular de maneira legítima seu convívio com os meios do direito positivo"21.

A possibilidade de adoção de ações afirmativas tem amparo nos arts. $3^{\circ} \mathrm{e}$ $5^{\circ}$, ambos da Constituição Federal/88 e nas normas da Convenção Internacional sobre a Eliminação de Todas as Formas de Discriminação Racial, integrada ao nosso 20 BALDI, César Augusto. As comunidades quilombolas e o seu reconhecimento jurídico. 2008. Disponível em: http://6ccr.pgr.mpf.mp.br/documentos-e-publicacoes/artigos/ docs_artigos /artigo_cesar_augusto_baldi.pdf. Acesso em: 25 maio 2014, p.2)

21 HABERMAS, Jürgen. A inclusão do outro: estudos de teoria política. Edições Loyola. São Paulo. 2002, p.229. 
ordenamento jurídico pelo Decreto n. 65.810/69. A forma de implementação de ações afirmativas no seio de universidade e, no presente caso, as normas objetivas de acesso às vagas destinadas a tal política pública fazem parte da autonomia específica trazida pelo art. 53 da Lei n. 9.394/96, desde que observados os princípios da razoabilidade e da proporcionalidade. Portanto, somente em casos extremos a sua autonomia poderá ser mitigada pelo Poder Judiciário, o que não se verifica nos presentes autos. Segundo Baldi:

Existe uma dificuldade de reconhecer a própria diversidade étnicocultural, associado ao padrão de "monoculturas da mente", ou seja, a reprodução do saber científico, da linearidade do tempo, da escala universal, da lógica produtivista e da naturalização das diferenças. Ou seja, a produção do "diferente", do "outro", como "ignorante", "atrasado"/"arcaico"/" prémoderno","local"/"tradicional", "improdutivo" e "inferior"22.

O ingresso na instituição de ensino como discente é regulamentado basicamente pelas normas jurídicas internas das universidades, logo a fixação de cotas para indivíduos pertencentes a grupos étnicos, sociais e raciais afastados compulsoriamente do progresso e do desenvolvimento, na forma do art. $3^{\circ}$ da Constituição Federal/88 e da Convenção Internacional sobre a Eliminação de Todas as Formas de Discriminação Racial, faz parte, ao menos - considerando o nosso ordenamento jurídico atual - da autonomia universitária para dispor do processo seletivo vestibular.

\section{A VIOLAÇÃO À LIBERDADE DE CULTO}

O conceito de cultura, segundo Geertz, não possui referentes múltiplos nem qualquer ambiguidade fora do comum, pois denota um padrão de significados transmitido historicamente, incorporado em símbolos, um sistema de concepções herdadas expressas em formas simbólicas por meio das quais os homens comunicam, perpetuam e desenvolvem seu conhecimento e suas atividades em relação à vida ${ }^{23}$.

22 BALDI, César Augusto. Justiça Federal: Racismo, terras e Direitos Humanos. 2010. Disponível em: http://democraciaejustica.org/cienciapolitica3/sites/default/files/justica_federal_racismo_terras_e_direitos_humanos_-_cesar_baldi_2010.pdf. Acesso em: 25 maio 2014, p.6).

23 GEERTZ, Clifford. A interpretação das culturas. Rio de Janeiro, RJ: LTC Editora, 1989, p.66. 
Em um contexto religioso pode-se mencionar que os símbolos sagrados funcionam como referência para determinado povo. Eles objetivam as preferências levando a um senso comum nas condições de vida impostas e apoiam crenças. Neste sentido, pode-se dizer que a religião ajusta as ações humanas.

O homem possui uma dependência tão grande em relação aos símbolos e aos sistemas simbólicos a ponto de serem eles decisivos para sua viabilidade como criatura e, em função disso, sua sensibilidade à indicação e até mesmo a possibilidade de enfrentar um aspecto da experiência provoca ansiedade e intolerância. Em certos momentos, estudar a maneira como homens e mulheres vivem torna-se complexo, fala-se em estágios evolutivos, ideias e práticas. Segundo Geertz:

Podermos ver-nos confrontados com um mundo no qual simplesmente já não existam mais caçadores de cabeças, estruturas matrilineares ou pessoas que fazem a previsão do tempo através de vísceras do porco. As diferenças sem dúvida continuarão a existir- os franceses jamais comerão manteiga com sal. Mas os bons e velhos tempos de lançar viúvas na fogueira e do canibalismo não voltam mais ${ }^{24}$.

Não apenas os antropólogos, mas todos terão que aprender a compreender as diferenças mais sutis de ordem moral, estética, cognitiva e, acima de tudo, sobre valores e sua justificação.

Os usos da diversidade cultural, de seu estudo, sua descrição, sua análise e sua compreensão, tem menos o sentido de nos separarmos dos outros e separarmos os outros de nós, a fim de defender a integridade grupal e manter a lealdade do grupo, do que o sentido de definir o campo que razão precisa atravessar, para que suas modestas recompensas sejam alcançadas e se concretizem ${ }^{25}$.

Neste sentido, é importante tocar no assunto violência, pois a concentração de violência (tumultos, assassinatos, rebeliões e guerras civis), nos mostra o quanto se torna importante como tudo acontece e o que pode ser feito para impedir, bem como para mostrar que os conflitos em si, cegam os seus demandantes e da 24 GEERTZ. Clifford. Nova luz sobre a antropologia. Rio de Janeiro: Jorge Zahar Ed., 2001, p.68.

25 GEERTZ. Clifford. Nova luz sobre a antropologia. Rio de Janeiro: Jorge Zahar Ed., 2001, p. 80 
uma imagem enganosa ao conflito. "Existem questões mais profundas em ação do que a mera desrazão, a qual, afinal de contas, todas as iniciativas humanas estão sujeitas, e não apenas as que dizem respeito ao Sentido de tudo"26. Há uma busca pela identidade e seu reconhecimento, o que obriga o homem a tomar uma causa para si, para ser identificado em determinado grupo.

Não foram apenas identidades religiosas, mas também étnicas, linguísticas, raciais e difusamente culturais que ganharam maior destaque político nos anos decorridos desde que a descolonização destroçou os impérios de além-mar, da queda do Muro de Berlim, do colapso da União Soviética, e o fim da Guerra Fria, estas destroçaram as grandes relações de poder. A proliferação de identidades políticas autônomas estimula identidades específicas e intensamente sentidas. A projeção de grupos e lealdades religiosas definidas em todos os aspectos da vida coletiva faz parte de um movimento de construção de um novo mundo, diverso e irregular. Falando de um campo internacional, no contato de diferentes religiões, em que há crenças diferentes, a convivência é tensa.

As diferenças de crenças, às vezes muito radicais, são mais diretamente visíveis, com frequência crescente, e mais diretamente encontradas: prontas para a suspeita, a preocupação, a repugnância e a alteração. Ou, supondo eu, para a tolerância e a reconciliação, ou até para atração e a convenção - ainda que estas, no momento, não sejam exatamente comuns $^{27}$.

A religião, sem interioridade, sem uma sensação banhada em sentimento de que a crença importa, e importa tremendamente, de que a fé sustenta, cura, consola, corrige as injustiças, melhora a sorte, garante recompensas, explica, impõe obrigações, abençoa, esclarece, reconcilia, regenera, redime ou salva, faz-se por uma dose de convencionalismo. Será que algum credo chega a ser suficiente para seus fins? Será que a visão religiosa dá poder à pessoa que busca, para qualquer fim? Acredita-se que o fim é político, econômico, há um intuito de ambição dentro deste imaginário. Há uma distância entre as convenções religiosas e suas práticas, entre crença e comportamento, há uma separação entre o social 26 GEERTZ. Clifford. Nova luz sobre a antropologia. Rio de Janeiro: Jorge Zahar Ed., 2001, p. 156.

27 GEERTZ, Clifford. Nova luz sobre a antropologia. Rio de Janeiro: Jorge Zahar Ed., 2001, p.158. 
e o cotidiano. "A religião é, portanto, um sistema gerador de sociabilidade e de comunidade"28.

No caso do Brasil, onde as identidades étnicas e as suas heranças culturais confrontam-se em relações desiguais, suas raízes remontam o período colonial. A identidade brasileira continua tendo como referência a identificação do poder monárquico. Segundo menciona D'Adesky, em sua chegada ao novo território, os negros africanos foram imediatamente inseridos num diferente quadro simbólico religioso, numa ruptura total com a realidade anterior às sociedades africanas.

A relação dos negros com a sociedade colonial fora marcada no plano religioso pela conversão obrigatória à religião do senhor e por um passado de perseguição àqueles que tentaram se manter fiéis às práticas de seus ancestrais ${ }^{29}$. A proliferação de cultos de origem negra no Brasil mostra que as origens estão presentes, constituem elementos das camadas populares da sociedade as quais afirmam sua cultura e, apesar de todo o preconceito e discriminação, aos quais fora submetida, a religião africana conseguiu sobreviver no novo território. "Terreiros de candomblé, a umbanda e o espiritismo continuam sendo fonte de afirmação existencial étnica"30.

O que se observa é que, mesmo assim, atitudes discriminatórias continuam presentes, como se pode verificar em recente matéria publicada no site Carta Capital ${ }^{31}$, em que Willys escreve sobre fato ocorrido recentemente, em que a liberdade religiosa e os seus preceitos foram violados. Neste contexto especificamente sobre o candomblé e a umbanda, foram alvo de questionamento via sentença judicial, a qual violou princípios constitucionais, os quais pretendem o Estado laico.

Fatos como este ocorrem pelo fato deste debate ter sido sempre negligenciado, porque a parcela da sociedade ofendida se cala frente às imposições da cultura

28 D'ADESKY, Jacques. Pluralismo étnico e multiculturalismo: racismos e anti-racismos no Brasil. Rio de Janeiro: Pallas, 2009, p.52

29 D'ADESKY, Jacques. Pluralismo étnico e multiculturalismo: racismos e anti-racismos no Brasil. Rio de Janeiro: Pallas, 2009, p. 51

30 D'ADESKY, Jacques. Pluralismo étnico e multiculturalismo: racismos e anti-racismos no Brasil. Rio de Janeiro: Pallas, 2009, p.53

31 WYLLYS, Jean. Até na justiça, candomblé é alvo de intolerância. Disponível em: http:// www.cartacapital.com.br/sociedade/ha-ofensa-e-fundamentalismo-na-decisao-contrariaa-umbanda-e-ao-candomble-7480.html>. Acesso em: 04 jun. 2014. 
ocidental e dos seus efeitos nocivos à identidade de determinado grupo étnico. A sentença proferida na Justiça Federal do Rio de Janeiro ${ }^{32}$ (Processo $n^{\circ} 0004747$ 33.2014.4.02.5101) define que umbanda e candomblé "não são religiões". A decisão cita que estas celebrações não estão previstas em determinados livros como a Bíblia (cristã) e o Corão (livro sagrado do Islã). Tal definição mostra a incapacidade de definição por parte do magistrado, a partir de resposta a uma decisão em primeira instância do Ministério Público Federal, a qual solicitou a retirada do site de vídeos YouTube alguns vídeos de cultos evangélicos, os quais promovem a discriminação e a intolerância contra as religiões de matriz africana e seus adeptos, já que o Código Penal, em seu art. 208, estabelece como conduta criminosa, escarnecer de alguém publicamente, por motivo de crença ou função religiosa, impedir ou perturbar cerimônia ou prática de culto religioso, ou ainda vilipendiar publicamente ato ou objeto de culto religioso.

A qualidade intrínseca e distintiva reconhecida em cada ser humano que o faz merecedor do mesmo respeito e consideração por parte do Estado e da comunidade, implicando, neste sentido, um complexo de direitos e deveres fundamentais que assegurem a pessoa tanto contra todo e qualquer ato de cunho degradante e desumano, como venham a lhe garantir as condições existenciais mínimas para uma vida saudável, além de propiciar e propiciar e promover sua participação ativa e co-responsável nos destinos da própria existência e da vida em comunhão com os demais seres humanos, mediante o devido respeito aos demais seres que integram a rede da vida ${ }^{33}$.

Resta dúvida com relação ao conhecimento de determinado magistrado sobre religiões específicas para o julgamento, o que ora se faz questionar pelo reconhecimento da existência da ofensa, pois na sentença a Justiça Federal do Rio de Janeiro desqualificou os ofendidos; considerando que não "há crime se não há religião ofendida". Para tanto, a Justiça Federal do Rio conceituou umbanda e candomblé como cultos a partir de dois motivos cheios de preconceito: segundo a decisão, candomblé e umbanda deveriam ter um texto sagrado como fundamento, o que foi totalmente ignorado que religiões de matriz africana são fundadas nos princípios da transmissão oral do conhecimento, do tempo circular,

32 Ler texto da decisão em: http://procweb.jfrj.jus.br/portal/consulta/resconsproc.asp.

33 SARLET, Ingo Wolfgang. Dignidade da pessoa humana e direitos fundamentais na

Constituição Federal de 1988. 9. ed. Porto Alegre: livraria do advogado editora. 2012. 
e do culto aos ancestrais e, ainda, que candomblé e umbanda deveriam venerar a uma só divindade suprema e ter uma estrutura hierárquica.

Esta decisão cheia de preconceito é perceptível que não apresenta nenhum amparo de cunho antropológico, humanitário e de respeito à cultura de outro grupo. Percebe-se a necessidade de reconhecimento destes povos, os quais deixaram um legado histórico para o país, para a cultura brasileira.

A decisão judicial fere dispositivos constitucionais (art. $5^{\circ}$ VI) e também tratados internacionais como a Convenção Americana sobre Direitos Humanos, conhecida como Pacto de San Jose da Costa Rica, ratificada pelo Brasil em 1992, a qual dispõe sobre a garantia de não discriminação por motivo de raça, cor, sexo, idioma, religião, opiniões, políticas ou de qualquer outra natureza, origem nacional ou social, posição econômica, nascimento ou qualquer outra condição social. O pacto menciona que o direito à liberdade de consciência e de religião implica a garantia de que todos são livres para conservar sua religião ou suas crenças, ou de mudar de religião ou de crenças, bem como na liberdade de professar e divulgar sua religião ou suas crenças, individual ou coletivamente, tanto em âmbito público como em âmbito privado.

A Convenção Americana sobre Direitos Humanos, outro documento de suma importância, afirma que ninguém pode ser objeto de medidas restritivas que possam limitar sua liberdade de conservar sua religião ou suas crenças, ou de mudar de religião ou de crenças. Ou seja, a liberdade de manifestar a própria religião e as próprias crenças está sujeita unicamente às limitações existentes em leis e que se mostrem necessárias à proteção da segurança, da ordem, da saúde ou da liberdade, não apresentando limitações ou condicionamentos, como menciona o magistrado.

Ao ratificar esse Pacto, o Brasil assumiu desde 1992 o papel de reconhecer as diferenças étnicas e protegê-las de maneira a não deixar que a liberdade de culto seja violada. É visível o despreparo do Poder Judiciário, o qual tem a função de ordem e fazer valer a legislação vigente não o fazer, o que sugere, até em se tratando de linhas hermenêuticas, carência de compreensão da lei. Se há decisão conforme a consciência, usando as palavras do professor Lenio Streck, 
faz-se necessária uma nova compreensão acerca de direitos fundamentais e da legislação internacional ratificada pelo Brasil.

O ataque aos cultos de umbanda e candomblé é um ataque de viés racista, principalmente por se tratar de religiões praticadas, sobretudo por pobres e negros. O que não é reconhecido é a herança histórica, o legado que estes povos deixaram e deixam na construção do Brasil, Jessé de Souza menciona:

Essa hierarquia valorativa implícita e ancorada institucionalmente de forma invisível enquanto tal é que define quem é ou não 'gente', sempre segundo seus critérios contingentes e culturalmente determinados e, por consequência quem é ou não cidadão, na medida em que a eficácia da regra da igualdade, que constitui a noção de cidadania precisa estar efetivamente internalizada e incorporada pré-reflexivamente, também nesta dimensão subpolítica da opacidade cotidiana, para ter validade efetiva ${ }^{34}$.

No Brasil, assim como na América Latina, ponto primordial houve durante a apropriação política e discursiva pelas classes populares ${ }^{35}$ no contexto social. Neste período, a busca pelo reconhecimento de direitos tornou-se sinônimo de maiorias marginalizadas e pobres. Segundo Lopes, "a questão dos direitos humanos é o aparecimento do sujeito popular e marginalizado como sujeito ativo da defesa da dignidade humana"36.

A violência contra classes populares já existia durante este período e se estende até a atualidade. Um exemplo de violência contra a classe pobre no Brasil foram execuções e castigos feitos aos negros e aos índios que ocorreram há um século. Estas relações devem ser compreendidas não apenas pelo lado violento, mas do conteúdo dos direitos sociais e econômicos que se relacionam aos movimentos populares.

Segundo Lopes,

[...] ocorre uma ampliação da pauta dos direitos humanos que passa a abranger as condições de sobrevivência (reprodução), isto é, os direitos econômicos. Como o ordenamento jurídico não garante o direito de

34 SOUZA, Jessé. A construção social da subcidadania: para uma sociologia política da modernidade. Belo Horizonte: Ed. UFMG; Rio de Janeiro: IUPERJ, 2003, p. 180

35 LOPES, José Reinaldo de Lima. Direitos sociais: teoria e prática. São Paulo: Método, 2006.

36 LOPES, José Reinaldo de Lima. Direitos sociais: teoria e prática. São Paulo: Método, 2006, p. 34. 
quem não tem, as reivindicações são mais políticas do que jurídicas ${ }^{37}$.

Nota-se que direitos sociais neste período passam a ser conquistados mediando reivindicações sociais e movimentos coletivos. A partir daí passa-se a um nível em que os direitos humanos tornam-se direitos de cidadania, pois são instrumentos criados para defender a pessoa humana não de um indivíduo qualquer, mas do exercício abusivo do poder político. A vítima desta violação é quase sempre subordinada ao autor, o qual acaba por violar sua dignidade. Como exemplo, tem-se o abuso de poder do Estado, que é ameaça permanente, na maioria das vezes, abuso de poder econômico.

Espera-se do poder Judiciário é que saiba reconhecer a importância destes povos e que se faça justiça para que episódios como este de intolerância e ganância contra cultos e igrejas não ocorra, e que se possa assegurar a pluralidade religiosa pautada no respeito e na dignidade sobre as religiões.

[...] concretizações da dignidade da pessoa humana, mas também pelo fato de que da dignidade decorrem, simultaneamente, obrigações de respeito e consideração (isto é, de sua não violação) mas também um dever de promoção e proteção, a ser implementado inclusiveconsoante já referido relativamente aos assim designados direitos sociais- por medidas positivas não estritamente vinculadas ao mínimo existencial $[. . .]^{38}$.

A busca de padrões abrangentes deve ser simplesmente abandonada, como um resto da busca antiquada do eterno, do real, do essencial e do absoluto. Não existem, segundo se afirma, narrativas mestras sobre a identidade, a tradição, a cultura ou qualquer outra. O que há são acontecimentos, pessoas e fórmulas incoerentes ${ }^{39}$.

Fora noticiado que o Ministério Público Federal recorreu dessa decisão e que houve uma retificação por parte do magistrado, o que ocorreu devido à intensa repercussão do caso. Segundo noticiado, o juiz da $17^{a}$ Vara Federal do Rio de 37 LOPES, José Reinaldo de Lima. Direitos sociais: teoria e prática. São Paulo: Método, 2006, p.38.

38 SARLET, Ingo Wolfgang. Dignidade da pessoa humana e direitos fundamentais na Constituição Federal de 1988. 9. ed. Porto Alegre: livraria do advogado editora. 2012, p. 118.

39 GEERTZ, Clifford. Nova luz sobre a antropologia. Rio de Janeiro: Jorge Zahar Ed., 2001, p.194. 
Janeiro, Eugênio Rosa de Araújo, reviu a sentença em que havia declarado que candomblé e umbanda não eram religiões, e sim cultos. A mudança foi divulgada em nota pela assessoria de imprensa da Justiça Federal do Rio de Janeiro. No documento o juiz admite o erro e modifica parte do conteúdo da sentença. Ele afirma ainda que "o forte apoio dado pela mídia e pela sociedade civil, demonstra, por si só, e de forma inquestionável, a crença no culto de tais religiões" ${ }^{40}$.

A Carta Constitucional, em harmonia com a concepção contemporânea de Direitos Humanos, demonstra sua universalidade e indivisibilidade de direitos. Ela consagra a universalidade de direitos à medida que estabelece dignidade da pessoa humana como valor primordial para o Estado Democrático de Direito e a indivisibilidade ao colocar ao lado da categoria de direitos civis e políticos a categoria de direitos econômicos, sociais e culturais como direitos e garantias fundamentais ${ }^{41}$.

Construir o papel social e psicológico da religião não está relacionado ao fato de encontrar relações entre os rituais específicos e os laços sociais seculares específicos. Trata-se de compreender de que maneira as noções dos homens e as disposições as quais estas induzem neles dão um colorido a seu sentido do racional, do prático, do humano e do moral. E mais, até onde isso alcança e quais são os resultados efetivos para a compreensão da religião.

Discutir o papel do culto dos ancestrais na regulamentação da política, dos festins, da adoração, da divinização para reforço do controle social ou dos ritos de iniciação não constituem uma análise de crenças, pois há necessidade de uma análise teórica no campo simbólico, o que demanda um conhecimento profundo sobre determinada religião.

\section{PLURALISMO JURÍDICO}

Pensar a questão do pluralismo é uma tentativa de buscar outra direção ou outro referencial epistemológico que atenda à modernidade do século XXI,

40 Notícia disponível no site: <http://negrobelchior.cartacapital.com.br/2014/05/21/juiz-reconsidera-e-diz-que-candomble-e-umbanda-sao-religioes/>. Acesso em: 25 de maio de 2014.

41 BARROSO, Luis Roberto. Interpretação e aplicação da Constituição. 7. ed. São Paulo: Saraiva, 2009, p.430. 
as quais acompanham com dificuldade as mudanças nas Ciências Humanas e do Direito. Trata-se de compreendê-lo como uma ruptura de ações, mitos e expressões na história social.

Segundo Wolkmer, trata-se da formulação do pluralismo como paradigma alternativo no âmbito da cultura jurídica, o que pressupõe pensar e adequar a proposta prático-teórica tendo em conta condições existenciais, materiais e culturais refletidas pela globalidade sociopolítica ${ }^{42}$.

O pluralismo jurídico deve ser visualizado como fenômeno de possibilidades e dimensões de universalidade cultural, como modelo que incorpora condicionantes inter-relacionados formal e materialmente adequados às especificidades e às condições históricas de sociedades. Por isso se menciona que o pluralismo provém não apenas da extensão dos conteúdos ideológicos, dos horizontes sociais e econômicos, mas, sobretudo, das situações de vida e diversidades culturais. "O reconhecimento do pluralismo na perspectiva da alteridade e da emancipação revela o locus de coexistência para uma compreensão crescente de elementos multiculturais criativos, diferenciados e participativos"43.

Percebe-se que o conteúdo do pluralismo está voltado para a construção de um espaço social de mediação que se contrapõe as duras ações do Estado.

Coloca Wolkmer que:

[...] critério valorativo capaz de distinguir o pluralismo enquanto sistema que se opõe ao monismo unificador e homogêneo é a sua natureza fluida e mutável centrada na diversidade. Esta na raiz da ordem pluralista a fragmentação, a diferença e a diversidade. Tratase de admitir a diversidade de seres no mundo, realidades díspares, elementos ou fenômenos desiguais e corpos sociais semi-autônomos irredutíveis entre si. O sistema pluralista provoca a difusão, cria uma normalidade estruturada na proliferação das diferenças, dos dissensos e dos confrontos ${ }^{44}$.

42 WOLKMER, Antonio Carlos. Pluralismo jurídico: fundamentos de uma nova cultura no Direito. 3. ed. Editora Alfa Omega. São Paulo. 2001. P.170.

43 WOLKMER, Antonio Carlos. Pluralismo jurídico: um espaço de resistência na construção de direitos humanos. In: Pluralismo jurídico: os novos caminhos da contemporaneidade. Wolkmer, Antonio Carlos, NETO, Francisco Q. Veras, LIXA, Ivone M. (Orgs). São Paulo: Saraiva, 2010.p. 41.

44 WOLKMER, Antonio Carlos. Pluralismo jurídico: fundamentos de uma nova cultura no 
À medida que a natureza humana é motivada por necessidades concorrentes, por disposições de vida, marcada por conflitos de interesses e pela diversidade cultural e religiosa, o pluralismo resguarda-se por meio de regras de convivência pautadas pelo espírito de indulgência. A tolerância está associada à liberdade humana, mas igualmente ao direito de autodeterminação, em que cada indivíduo classe ou movimento coletivo possui sua identidade própria e possui diferenças funcionais frente aos outros. "Assim, a reinvenção do pluralismo, como um novo paradigma, implica transpor as diretrizes da cultura sócio-política identificadas com o tradicionalismo dos pluralismos 'orgânico- corporativista' e 'neoliberal-capitalista'"'45.

Neste sentido, a proposta de pluralismo deve adequar-se às exigências de um processo político participativo e inserido no espaço global e local, trabalhando em um espaço pela sociedade democrática. Esta luta pelo espaço democrático atua no sentido de fazer-se reconhecer perante o outro, que num primeiro momento é de reconhecimento dos desiguais. Com isso, percebe-se que, com o pluralismo, expressa-se um choque de normatividades, cabendo aos grupos minoritários lutar para fazer prevalecer o seu direito.

O que importa é descobrir canais que viabilizem a participação dos indivíduos e dos grupos sociais no processo de elaboração do Direito, no caso aqui mencionado para a proteção das minorias e dos grupos vulneráveis, a fim de que se possam fazer valer interesses populares e conteúdos novos, substituindo as tradições hegemônicas.

Há de se designar o pluralismo jurídico como a multiplicidade de práticas jurídicas existentes num mesmo espaço sociopolítico, interagidas por conflitos ou consensos, podendo ser ou não oficiais e tendo a sua razão de ser nas necessidades existenciais, materiais e culturais ${ }^{46}$.

Wolkmer menciona que o reconhecimento de outra cultura jurídica, marcada pelo pluralismo de tipo comunitário-participativo e pela legitimidade construída por meio das práticas internalizadas de sujeitos sociais, permite Direito. 3. ed. Editora Alfa Omega. São Paulo. 2001. P.176.

45 WOLKMER, Antonio Carlos. Pluralismo jurídico: fundamentos de uma nova cultura no Direito. $3^{a}$ ed. Editora Alfa Omega. São Paulo. 2001. P.181.

46 WOLKMER, Antonio Carlos. Pluralismo jurídico: fundamentos de uma nova cultura no

Direito. $3^{a}$ ed. Editora Alfa Omega. São Paulo. 2001. P.219. 
avançar na redefinição e na afirmação de direitos humanos numa perspectiva de interculturalidade ${ }^{47}$.

Estruturas como a brasileira, marcadas por uma cultura autoritária, centralizadora e excludente, impõem-se identificar, como ocorre a reordenação do espaço comunitário, a construção de uma verdadeira cidadania aliada ao desenvolvimento de uma democracia participativa que tenha como meta a efetiva participação popular. A construção de uma sociedade democrática fundada em bases necessárias para a consolidação de identidades locais. Há uma democratização da sociedade, do Estado e da cultura, para que possa ocorrer a melhoria da qualidade de vida, a humanização e o fortalecimento de democracias Estatais locais.

\section{CONSIDERAÇÕES FINAIS}

O estudo sobre a origem das culturas e dos povos teve por consequência a revalorização do paradigma das identidades junto às Ciências Humanas. Tiveram-se antes mudanças maciças, continentais, na sensibilidade religiosa, cujo impacto na vida humana, como se pode perceber, apesar do caráter maltrapilho que elas tiveram, foi radical e profundo, constituindo uma vasta reformulação do julgamento e da paixão.

Abordou-se no presente artigo o debate acerca da necessidade de reconhecimento dos direitos do grupo minoritário afrodescendente, frente a preceitos de desigualdade, dignidade, respeito e descumprimento de direitos fundamentais em âmbito nacional e descumprimento dos Direitos Humanos com base em análise de jurisprudência da Justiça Federal do Rio de Janeiro.

O que se compreende a partir deste estudo é que a sociedade brasileira continua propagando atitudes discriminatórias advindas de um período histórico, de colonização, ainda muito presente no tocante às relações sociais. E que, mesmo com teorias e práticas de estudos presentes no ordenamento jurídico, demonstra-se com a jurisprudência mencionada que nossos magistrados não estão suficientemente preparados para discutir tais demandas.

47 WOLKMER, Antonio Carlos. Pluralismo jurídico: um espaço de resistência na construção de direitos humanos. In: Pluralismo jurídico: os novos caminhos da contemporaneidade. Wolkmer, Antonio Carlos. NETO, Francisco Q. Veras, LIXA, Ivone M. (Orgs). São Paulo: Saraiva, 2010.p. 43 
Ora, se a população brasileira é composta por descendentes africanos, bem como europeus, não cabe ao poder judiciário brasileiro definir qual o tipo de culto religioso deve ser seguido, e sim manter o que menciona a legislação (sendo o legislador o legitimado para esta definição), deixando-o livre para determinada escolha.

O que se leva a crer que ainda há necessidade de reconhecimento de direitos no sentido de dirimir fatores políticos e ideológicos sobre a colonização brasileira, ainda que o reconhecimento de outras culturas deve se engajar ao pluralismo, objetivando uma legitimidade no sentido de avançar na redefinição e na afirmação de direitos humanos numa perspectiva intercultural.

A proliferação de cultos de origem negra no Brasil mostra que as origens estão presentes, constituem elementos das camadas populares da sociedade, as quais afirmam sua cultura e, apesar de todo o preconceito e discriminação, aos quais fora submetida, a religião africana conseguiu sobreviver no novo território. Neste sentido, é importante reconhecer que o direito de culto reconhecido pela Constituição Federal se faça valer e que construir o papel social da religião não está relacionado ao fato de encontrar relações entre os rituais específicos e os laços sociais seculares específicos, mas se trata de compreender de que maneira as noções dos homens e as disposições as quais estas induzem neles dá-se um sentido do racional, humano e moral.

\section{REFERÊNCIAS}

BALDI, César Augusto. Justiça Federal: Racismo, terras e Direitos Humanos. 2010. Disponível em: http://democraciaejustica.org/cienciapolitica3/sites/ default/files/justica_federal_ racismo_terras_e_direitos_humanos-cesarbaldi 2010.pdf. Acesso em: 25 maio 2014.

BALDI, César Augusto. As comunidades quilombolas e o seu reconhecimento jurídico. 2008. Disponível em: http://6ccr.pgr.mpf.mp.br/documentos-e-publicacoes/artigos/docs_ artigos/artigo_cesar_augusto_baldi.pdf. Acesso em: 25 maio 2014.

BARROSO, Luis Roberto. Interpretação e aplicação da Constituição. 7. ed. São Paulo: Saraiva, 2009.

CANCLINI, Néstor Garcia. Diferentes, desiguais e desconectados: mapas da interculturalidade. 3. ed. Rio de Janeiro: Ed. da UFRJ, 2009. 
D'ADESKY, Jacques. Pluralismo étnico e multiculturalismo: racismos e anti-racismos no Brasil. Rio de Janeiro: Pallas, 2009.

GIDDENS, Anthony. As consequências da modernidade. São Paulo: Ed. Unesp, 1991

GEERTZ, Clifford. A interpretação das culturas. LTC Editora, Rio de Janeiro, RJ. 1989.

GEERTZ, Clifford. Nova luz sobre a antropologia. Rio de Janeiro: Jorge Zahar Ed., 2001.

GOHN, Maria da Glória. Movimentos sociais e redes de mobilizações civis no Brasil contemporâneo. 2. ed. Petrópolis, RJ: Vozes, 2010.

GONÇALVES, Luiz Alberto Oliveira; SILVA, Petronilha B. Gonçalves e. $\mathbf{O}$ jogo das diferenças: o multiculturalismo e seus contextos. 4. ed. Belo Horizonte: Autêntica, 2006.

HABERMAS, Jürgen. A inclusão do outro: estudos de teoria política. EdiçõesLoyola. São Paulo. 2002.

HALL, Stuart. A identidade cultural na pós-modernidade. 11. ed. Trad. Tomaz Tadeu da Silva e Guacira Lopes Louro. Rio de Janeiro: DP\&A, 2006.

HONNETH, Axel. Luta por reconhecimento: a gramática moral dos conflitos sociais. Trad. de Luiz Pepa. São Paulo: Ed. 34, 2003.

LOPES, José Reinaldo de Lima. Direitos sociais: teoria e prática. São Paulo: Método, 2006.

SARLET, Ingo Wolfgang. Dignidade da pessoa humana e direitos fundamentais na Constituição Federal de 1988. 9. ed. Porto Alegre: livraria do advogado editora. 2012.

SOUZA, Jessé. A construção social da subcidadania: para uma sociologia política da modernidade. Belo Horizonte: Ed. UFMG; Rio de Janeiro: IUPERJ, 2003. P. 180

TAYLOR, Charles. Multiculturalismo. Lisboa, Portugal: Instituto Piaget, 1994.

WILLEMAN, Estela Martini; LIMA, Guiomar Rodrigues de. $\mathbf{O}$ preconceito e a discriminação racial nas religiões de matriz africana no Brasil. Disponível em: < http://www.uniabeu.edu. br/publica/index.php/RU/article/view/60/120>. Acesso em: 11 de junho de 2014.

WOLKMER, Antonio Carlos. Pluralismo jurídico: fundamentos de uma nova cultura no Direito. 3. ed. Editora Alfa Omega. São Paulo. 2001.

WOLKMER, Antonio Carlos. Pluralismo jurídico: um espaço de resistência na construção de direitos humanos. In: Pluralismo jurídico: os novos caminhos da contemporaneidade. 
Wolkmer, Antonio Carlos, NETO, Francisco Q. Veras, LIXA, Ivone M. (Orgs). São Paulo: Saraiva, 2010.p.

WYLLYS, Jean. Até na justiça, candomblé é alvo de intolerância. Disponível em: < http:// www.cartacapital.com.br/sociedade/ha-ofensa-e-fundamentalismo-na-decisao-contraria-aumbanda-e-ao-candomble-7480.html>. Acesso em: 04 jun. 2014.

Recebido em: fev/2015

Aprovado em: mai/2015 